\title{
Republic of Moldova: Joint Staff Advisory Note of the Poverty Reduction Strategy Paper
}

The attached Joint Staff Advisory Note (JSAN) of the Poverty Reduction Strategy Paper for the Republic of Moldova, prepared jointly by the staffs of the World Bank and the IMF, was distributed with the member country's Poverty Reduction Strategy Paper (PRSP) to the Executive Boards of the two institutions. The objective of the JSAN is to provide focused, frank, and constructive feedback to the country on progress in implementing its Poverty Reduction Strategy (PRS).

Copies of this report are available to the public from

International Monetary Fund • Publication Services

$70019^{\text {th }}$ Street, N.W. • Washington, D.C. 20431

Telephone: (202) 623-7430 • Telefax: (202) 623-7201

E-mail: publications@imf.org •Internet: http://www.imf.org

\section{International Monetary Fund} Washington, D.C. 



\title{
INTERNATIONAL DEVELOPMENT ASSOCIATION \\ INTERNATIONAL MONETARY FUND
}

\section{REPUBLIC OF MOLDOVA}

\section{Joint Staff Advisory Note on the Poverty Reduction Strategy (National Development Strategy) 2008-2011}

\author{
Prepared by Staffs of the International Development Association (IDA) \\ and the International Monetary Fund (IMF) \\ Approved by Shigeo Katsu (IDA) and \\ Juha Kähkönen and Anthony R. Boote (IMF)
}

February 20, 2008

\section{OVERVIEW}

1. On January 18, 2008, the Government of Moldova formally approved the second Poverty Reduction Strategy - known as the National Development Strategy (NDS) 2008-2011. Incorporating key elements of its predecessor, the Economic Growth and Poverty Reduction Strategy Paper (EGPRSP), the NDS unifies in one document the government's poverty reduction strategy and development vision, though the EU-Moldova Action Plan remains a separate strategic document. As with the EGPRSP, the inclusive and participatory process in elaborating the NDS will also contribute to implementation. The EGPRSP proved to be an effective mechanism to mobilize donor support, and development partners have already indicated their intentions to align their strategies and programs with the NDS.

\section{The NDS presents a comprehensive medium-term strategy that focuses on five} cross-cutting national priorities: (1) strengthening democracy based on the rule of law and respect for human rights; (2) settlement of the Transnistria conflict and reintegration of the country; (3) enhancing the national economic competitiveness; (4) human resource development, enhancing employment, and promoting social inclusion; and (5) regional development. Moldova is a small, open economy, heavily dependent on agriculture, and with a large proportion of its labor force working abroad, the focus of the NDS is appropriate. Further, with the recent expansion of EU membership (which now includes neighboring Romania) - together with low labor costs and educated work force-Moldova is now advantageously positioned for greater integration into the European market, shifting its dependence away from more traditional CIS markets. The recent autonomous trade preferences agreement with the EU also provides significant opportunities. The economic objectives of the NDS are consistent with the aim of consolidating these advantages. 


\section{MAIN ACHIEVEMENTS OF THE EGPRSP}

\section{The EGPRSP was presented to the Boards of IDA and the IMF in November}

2004. Due to the ambitious nature of some actions, the implementation period was extended through 2007. The EGPRSP provided, for the first time, a framework against which program implementation could be monitored. Two annual evaluation reports (March 2006 and March 2007) were prepared, and the final report is scheduled to be finalized at the end of March 2008. The 2007 report noted that although maternal health improved (from 23.5 deaths per 100,000 births in 2004 to 16.0 in 2006), and child mortality decreased, the incidence of HIV rose, almost doubling among 15-24 year-olds. Progress on other Millenium Development Goals, such as eradication of extreme poverty, universal primary education, and environmental sustainability was mixed.

4. During the EGPRSP implementation period, economic growth continued to be strong (exceeding the target average of 5 percent per annum), despite external shocks. Macroeconomic management remained prudent (with small fiscal surpluses in most years) contributing to significant reductions in public external debt (from 47 to 29 percent of GDP). Major reform efforts were undertaken to reduce administrative and regulatory barriers to business (simplifying a large number of regulations and cutting the number of required licenses) and increase domestic competitiveness. There was substantial reform of the health care system (introduction of mandatory insurance) and improvements in the methodology for estimating poverty rates. The Government also launched an ambitious program to reform the public administration. As a result of these efforts, confidence in the authorities' commitment and ownership to the reform agenda has been greatly enhanced.

\section{The last Joint Staff Advisory Note (JSAN) highlighted some challenges and} provided advice on key priorities for strengthening the strategy and promoting its effective implementation. Among these were the need to: maintain a macroeconomic framework that takes the country's external vulnerabilities into account; ensure better strategic linkage between the annual budgets, the MTEF and the PRSP; restructure public finances to support growth promoting infrastructure; create a better business environment; and strengthen the targeting efficiency of social assistance. As this JSAN notes, the Government has made progress on all of these issues and has strengthened these areas in the NDS.

\section{Macroeconomic Situation}

\section{Macroeconomic performance has been robust, but Moldova is increasingly} facing many of the strains experienced by other countries undergoing transition. During the period covered by the EGPRSP, the authorities have established a good track record of macroeconomic stability, despite external shocks. GDP growth in 2006 and 2007 slowed to 4 percent. Over the EGPRSP period (2004-2007) cumulative growth was about 25 percent. Prudent macroeconomic policy has been maintained, with the government budget recording small surpluses in most years. Rising energy prices complicated anti-inflationary efforts and, 
along with the restrictions imposed on Moldova wine exports to Russia, contributed to the worsening of the current account balance. Sizeable capital inflows have added to appreciation pressures, and resulted in a substantial accumulation of international reserves. The authorities have set in motion some of the plans to sustain growth, including investing in much-needed infrastructure and furthering public administration reform efforts. The NDS targets annual growth rates of about 5.6 percent over 2008-10. Though the growth and poverty reduction objectives are underpinned by a coherent medium-term macroeconomic framework, this would need to be adjusted as the economic situation evolves. Staffs also welcome the continued emphasis in the NDS on maintaining macroeconomic stability.

\section{The pattern of growth is also changing, with developments in Moldova} increasingly mirroring those in other transition economies. While large inflows of remittances continue, information from the banks and investment data suggest that they are increasingly flowing into investment rather than consumption. FDI has also picked up and is estimated to have reached 12 percent of GDP in 2007, up from 7 percent in 2006. In addition, construction and trade are growing rapidly, while agricultural employment has declined. There has been a shift of employment within the industrial sector away from winemaking into manufacturing, particularly to textiles, where Moldova's low labor costs continue to provide a comparative advantage. This has led to an increase in private sector employment and a recent slowdown in the pace of emigration through 2006. Continued streamlining of labor market and business regulations will be crucial to continuing this trend. The authorities should integrate the implementation of the NDS priorities into the overall economic strategy laid out in the medium-term expenditure framework.

8. Moldova's debt outlook is favorable, with a low risk of debt distress. In the face of some severe shocks in 2006, the Moldovan authorities did not resort to excessive borrowing. This led to an agreement with the Paris Club and commitments by the Consultative Group that have bolstered debt sustainability. Given Moldova's development needs, there appears to be room for modest additional borrowing for infrastructure and other high priority projects, as long as such borrowing remains prudent and prioritized within the medium-term fiscal framework. However, this prioritization has not yet taken place, suggesting caution when assessing projects. Absorptive capacity will likely be a more binding constraint than debt sustainability, and since Moldova is now above the IDA-only threshold, opportunities for concessional borrowing should be appropriately examined in the near term.

\section{While the authorities see upside risks to the outlook, the current favorable} environment is still fragile. In particular, smooth convergence will depend on a strong fiscal and monetary stance to bring inflation down quickly and allow more policy flexibility when Moldova faces inevitably mounting capital inflows and appreciation pressures. Indeed, inflation, which has particular adverse effects on the poor, is the main macroeconomic challenge in the short term. The authorities are pursuing a more aggressive monetary stance, and are also preparing to move to inflation targeting over the medium term, although many of the details have yet to be determined. In addition, Moldova likely faces further energy 
price increases. At about 43 percent of GDP, the size of the government is excessive for a country at Moldova's level of development, and limits growth potential. Gradual retrenchment and restructuring of the public sector over the medium term will be essential to provide room for the private sector. At the same time, the recent tax and capital amnesty was not the ideal way to manage the tax burden, and should not be repeated. Finally, a look at Moldova's neighbors clearly shows the importance of structural reforms, productivity improvements and a healthy financial sector for boosting longer-term growth prospects.

\section{Poverty Analysis}

10. About a third of the population lives in poverty, but extreme poverty is low. In 2006, absolute poverty was estimated at 30.2 percent of the population, but only 4.5 percent of the population lived in extreme poverty. While the incidence of absolute poverty is high, it is lower for those living in cities, at 20.6 percent, implying a higher incidence in towns and rural areas. These levels of poverty are an important incentive for the labor force to look abroad for better opportunities.

11. The new household survey has improved monitoring capabilities but precludes analysis of trends. The Household Budget Survey (HBS), the main source of data for measuring living standards, was substantially revamped in 2006. Changes included revisions to the questionnaire and the sampling framework to make the survey more representative. The methodological revisions in 2006 make comparisons with previous poverty numbers problematic. As such, little is known, for example, about how poverty and household welfare have evolved in response to recent external shocks. The methodological break also prevents the evaluation of poverty and distributional impacts of any recent reform or program.

\section{Staffs encourage the authorities to explore technical options for assessing trends} in monetary and non-monetary dimensions of poverty. While the poverty rate from the 2005 survey cannot be compared with those from 2006 , it may be possible to compare selected social indicators across years and even develop a comparable set of poverty indicators over time, using a set of variables correlated with poverty that are common across years. Such an effort, not currently made in the NDS, would be an important step towards helping resolve some puzzles in the differences in disaggregated poverty rates between 2005 and 2006. For example, the rate of poverty among pensioners in 2006 appears substantially higher than in previous years, while the gap between rural and urban poverty rates is smaller in 2006 than beforehand.

\section{Despite technical issues in the comparability of poverty numbers over time,} much of our understanding of the static poverty profile remains unchanged. Poverty still remains primarily a rural phenomenon, with households in the rural areas experiencing the highest poverty rate. The data also consistently suggest that the poverty rates among pensioners, farmers and agricultural workers are the highest. Because it is clear that poverty remains a rural phenomenon, any strategy aimed at alleviating poverty must address the 
economic opportunities (or lack thereof) in rural areas. The impact of the recent drought on farmers' incomes, as well as the social impact of the likely future recurrence of droughts, should also be a policy concern. In addition, improving the quality of public service provision - including in the areas of education, health, and basic infrastructural servicesand the effort to provide economic opportunities for disadvantaged groups are critical to address non-income aspects of poverty. The effort to address social exclusion in the labor market and promote equal opportunity, for example, is a welcome initiative.

\section{National Medium-term Priorities}

\section{Staffs welcome the comprehensive and strategic nature of the NDS.}

Macroeconomic stability is correctly identified as a prerequisite. Among the key challenges confronting Moldova will be realizing a settlement to the Transnistrian conflict and reintegrating the country. A number of donor partners have been working with the Government to address this issue in a broader context, including the European Neighborhood Policy. Staffs have indicated their willingness to provide analytical and technical assistance on the economic challenges implied by reintegration.

\section{A. Governance and Anti-Corruption}

\section{Improving governance and combating corruption in Moldova has proved be} quite challenging. Moldova has received assistance in upgrading legal and institutional capacity to address instances of corruption and money laundering as well as the implementation of new legislative and policy instruments. The EU-Action Plan and the EGPRSP provided sound framework and anti-corruption goals. Overall, results from the implementation of these initiatives have been slow to materialize.

\section{The NDS signals a renewed commitment on the part of the Government to} address corruption more effectively. Staffs view that NDS appropriately defines the scope of this issue and matches well recognized governance and anti-corruption needs with Government actions. The NDS identifies a number of important priorities (e.g., independence of the judiciary and further consolidation of the judicial system, reform the extensive powers of the General Prosecutor, and emphasis on preventive anti-corruption efforts), but lacks policy implementation detail. Given the current extensive legislative backlog in this area (with approval of some laws pending after two years), the sequencing of specific priorities and deadlines still needs to be addressed. The selection of indicators and monitoring arrangements presented in the NDS are not very strong measures of the quality of justice or its outcomes and there are no actionable anti-corruption indicators. Finally, the discussion would have benefited from an elaboration of some overarching strategic aspirations, such as convergence to EU governance space and standards, or government modernization. 


\section{B. Enhancing Competitiveness}

\section{The NDS recognizes the need to improve the competitiveness of Moldova's} economy to achieve sustained economic growth and poverty reduction. It also acknowledges that the country's current competitive position based on low labor costs is not sustainable over the longer term, and needs to be replaced by the efficiency and qualitybased competitiveness. To this effect, the report identifies five specific policy priorities that should create pre-conditions for enhanced competitiveness-improved business environment, promotion of SME sector, improved efficiency of enterprises, research and innovation development, and physical infrastructure development.

18. While staffs generally concur with these priorities, there should be more explicit recognition in the strategy that most of the competitiveness gains would need to come from the private enterprise sector. Staffs therefore welcome the stated intention of the authorities to continue the comprehensive reform of business regulatory framework aimed at creating a conducive climate for private firm entry, operations, and exit. The recent moves to liberalize labor markets, such as the recent one to amend wage-setting restrictions, should also be continued. While the focus on the development of a strong SME sector is appropriate, staffs caution against the use of support mechanisms not based on firm market principles (e.g., subsidized credit) that could result in misallocation of scarce public resources. Finally, the NDS could put more emphasis on developing the absorptive capacity of domestic enterprises, since experience from other transition economies suggests that most productivity gains at the firm level result from technology and knowledge transfer rather than internal innovation.

19. Staffs are also encouraged that the authorities have been taking steps to reorient and downsize the public sector. They have revived the stalled privatization process, and the recently published privatization list is a welcome early indication that the Government may be willing to reduce the role of the state. Staffs note the need to accelerate strategies for liberalization and privatization of key strategic sectors, such as telecommunications, and ensure a transparent and rules-based privatization program. The Government should also ensure that public sector downsizing adequately addresses any impact on poverty resulting from the reforms. In addition, the NDS correctly puts a high priority on public administration reform (PAR), identifying it as a prerequisite. However, Moldova has much that remains to be accomplished in this area and hence many of these "prerequisites" will remain outstanding over the life of the NDS itself. Staffs of both the World Bank and the IMF will continue to work with the authorities to integrate the PAR objectives into annual NDS action plans.

20. Promoting public-private partnerships (PPPs) to leverage the private sector need to be carefully assessed. With limited government capacity, PPPs provide an opportunity to leverage private resources for initiatives with significant public good components. When well designed, there are clear benefits. However, experience in many 
countries has shown that PPPs can also be used to move commitments off the fiscal balance sheet, with serious negative consequences from contingent liabilities being realized.

\section{There is limited discussion in the NDS on the financial sector despite its} important role in channeling resources in the economy toward productive use. Staffs note that positive steps have been taken in recent years to improve the lending environment through improved banking supervision, entry of foreign strategic investors, and unified supervision of non-bank financial institutions (NBFI) through the National Commission for Financial Markets (NCFM). Staffs urge the authorities to continue to pursue this agenda with vigor, including deepening financial intermediation, strengthening the corporate governance of banks and facilitating the healthy growth of NBFI sector. Greater competition in banking sector should be encouraged in order to reduce the cost of intermediation. Strengthening of regulatory and supervisory regime non-bank financial sector also remains a priority, in view of the systemic risks presented by the rapid growth of insurance sector, credit cooperatives, and other types of NBFIs.

\section{Human Resources Development}

22. The NDS recognizes that addressing human resource needs will be critical to Moldova's efforts to accelerate its economic development and poverty reduction. It addresses such needs comprehensively and covers the areas of education, health care, labor and social protection.

23. With respect to education, the NDS lays out an agenda for improving pre-school, secondary and vocational education. A wide range of programs and measures are identified in support of this objective. Staffs recommend the inclusion of additional measures, including strengthening accountability in education through greater decentralization and local participation following the planned consolidation of the schools network, diversification of providers of teacher training, introduction of an accreditation mechanism to ensure quality training, use of objective evaluations and assessments (including through participation in international evaluations to get adequate information on student learning), and the promotion of student-centered teaching and learning methods. The prioritization of these programs and measures will also be necessary. Parallel efforts in higher education reform are also warranted. These should aim at better aligning the educational system with European trends and requirements, as well as making it more relevant to labor market needs. Staffs urge the government to undertake further in-depth analysis of vocational and higher education.

\section{Health care reforms in the NDS rightly focus on further improving access to} services and improving health service quality. The NDS envisions continued strengthening of primary and preventive care services and modernizing secondary care services, including the development of alternative service delivery mechanisms such as home care, community care and palliative care. The emphasis on increased public-private 
partnerships in service delivery is also welcomed, albeit with caution as to the potential impact of contingent liabilities. To achieve stated health objectives, particular attention will have to be paid to improved medical education, increasing financial risk protection for the rural population and improving provider payment arrangements that provide the right incentives for health providers to both improve efficiency and deliver quality health services.

25. The NDS broadly acknowledges that the reform to the pension system, launched in 1999, is still incomplete. The pension system remains overly complex and difficult to administer. Among the key issues remaining to be addressed are the weak linkage between contributions and pensions and a smaller number of contributors supporting a growing number of pensioners as the population continues to age. Staffs note that the measures proposed in the NDS do not adequately address these issues. As proposed in the 1999 reform, there is a need to increase the current low retirement age, and calculate pensions based on actual contributions. Moreover, it does not have any proposals to improve contributions collection. The benefits formula could also be made more uniform across all participants. Finally, the proposed monitoring indicators could be improved and expanded.

\section{Staffs note that more work is needed before a private pillar of the pension} system can be introduced, as suggested in the NDS. This is particularly true in evaluating the preparedness of the regulatory environment, the financial markets, and the capacity of institutions to support a privately managed fully funded scheme. Further, the financial sustainability of the public scheme (including the fiscal impact of the transition) and the level of expected benefits from the funded scheme should be carefully evaluated before a privately managed funded scheme is introduced.

\section{Regional Development}

27. Generating economic growth outside the capital city is one of the key challenges the authorities address in the NDS. As the poverty analysis indicates, Moldova's transition to a market economy has been accompanied by a widening gap between the urban and rural sectors. Improving the performance of the agricultural sector will be essential for rural economic development. The NDS proposes to establish a regional development institutional framework to coordinate and finance regional initiatives.

\section{Given that agriculture is still very important in Moldova, staffs are concerned} that there is limited discussion in the NDS on how to modernize this sector. It would be beneficial if the NDS addressed some of the issues raised in the Agricultural Sector Strategy that has been developed by the Ministry of Agriculture and Food Industry. While the NDS appropriately identifies the key objectives in the sector - increasing efficiency and competitiveness and reducing vulnerability to natural disasters, such as drought - it does not address some of the key constraints to improving the agricultural competitiveness. Increased attention needs to be paid to ensuring that Moldovan farmers have access to the services they 
need to be more productive, including extension, training, and applied research. The continued reallocation of agricultural expenditures towards more growth-enhancing services and investments will be warranted. Staffs welcome the NDS formulation of improving the investment climate in agriculture. The instinct for state intervention nevertheless remains strong. Agricultural policies designed to subsidize certain producers or artificially lower food prices are counterproductive, and these policy objectives could be better addressed by improvements in the business environment and targeted social assistance.

29. The NDS could more effectively address the enormous environmental challenges on the horizon. The projected effects of climate change suggest the increased frequency and severity of natural disasters, such as droughts, floods, soil erosion and landslides. These in turn have enormous economic impacts, particularly on rural development and agricultural production. One urgent task would be to prepare a National Natural Hazards Risk Management and Adaptation Strategy and Action Plan outlining the relevant short, medium and long term activities that can mitigate the adverse effects of natural hazards and climate change.

30. The NDS recognizes that inadequate infrastructure is an impediment to socioeconomic development. Current spending levels on infrastructure are currently on an upward trend. The NDS should acknowledge that the Government's strategy towards these public infrastructure investments is contained in the road, energy and water supply and sanitation sectoral strategies. In a number of these sectors, with rising energy costs, there is a need to greatly improve the efficiency of energy use, improve demand side management, and reduce losses from the various networks. Further, more work is needed to ensure tariffsetting for utilities is adequate for continued provision of such services. Higher imported energy costs will necessitate higher utility tariffs and the government needs to assess whether plans for targeting of social assistance will adequately address the poverty implications of these rising energy costs.

\section{Participation, Monitoring and Evaluation}

\section{The NDS was discussed extensively with civil society and other stakeholders}

before adoption by the government. Staffs commend the government on the thorough and comprehensive nature of these consultations. A draft plan was prepared in the first half of 2007 , and the government then engaged in significant consultations with donors, nongovernmental organizations, and other stakeholders during the summer. In addition to Government approval of the strategy, Parliament endorsed the NDS on December 21, 2007.

32. The NDS established an institutional framework for monitoring and evaluation. Given the participatory nature of NDS preparation, Staffs commend the Government for retaining the participation council's role, which includes representatives of various NGO, private sector, and trade union stakeholders, developed under the EGPRSP in monitoring NDS implementation. 


\section{The NDS makes an effort to develop a comprehensive results framework by} including a number of key targets and indicators. In particular, Staffs note that the NDS lays out country-specific Millennium Development Goals (MDGs) with targets to be achieved with the NDS implementation period. Further, for each priority areas, the NDS lists a number of indicators to be monitored. However, given limited capacity to collect and analyze data, Staffs are concerned that the monitoring framework contains an excessive number of indicators not all of them well specified or immediately relevant. There is a need for further prioritization of these monitoring indicators with a focus on key measures. In the education sector, indicators seem to be too general to allow progress monitoring and evaluation. In some cases, monitoring indicators need to be added. For example, there are no specific performance indicators characterizing the pace of public administration reform and civil service reform, though public administration reform is characterized as a prerequisite for achievement of NDS priorities. Staffs also encourage the inclusion of measures that track improvements in the quality of health services.

\section{Staffs welcome government plans to implement the NDS and integrate it more}

fully into the fiscal process. Addressing some of the concerns expressed in the previous JSAN, the government has prepared an annual Action Plan to cost and operationalize the goals set forth in the NDS. This Action Plan will be revised annually, with the policy objectives incorporated into the medium-term expenditure framework and annual budgets. Staffs note that capacity constraints in a number of line ministries remain a serious impediment to the effective development and implementation of these annual action plans, but training efforts are ongoing.

\section{CONCLUSION AND SUGGESTED ISSUES FOR DISCUSSION}

\section{Bank and Fund staffs believe the NDS provides a good basis for poverty} reduction in Moldova, but implementation will be key. The focus on competitiveness, human resources, and regional development is appropriate given Moldova's current situation. The consolidation into one document of the priorities should enable efficient monitoring and coordination among donors offering assistance. The strong ownership of the reform strategy will also help shape both the World Bank and the IMF's assistance. Implementation risks, particularly those emerging from external terms of trade shocks, weakness in implementation capacity, and the political cycle need to be actively managed.

\section{A. Priority Actions}

36. Staffs recommend that special attention be given to the following areas for implementation:

a. Monitoring and evaluation. Need to continue strengthening the monitoring framework and capacity of key line ministries to develop and implement 
annual action plans, and integrate these actions into the medium-term expenditure framework.

b. Public Administration Reform. Given that PAR is recognized as fundamental to reform, the NDS could place greater emphasis on the need to have robust civil service management capacity.

c. Business environment. Staffs recommend that efforts at reducing administrative and regulatory barriers continue to be given a high priority for implementation, as Moldova still lags behind regional comparators in a number of indicators of competitiveness.

d. Physical infrastructure development. Moldova's aging infrastructure is increasingly becoming a significant bottleneck to growth. Along with roads, new investment in energy and telecommunications infrastructure needs to be accelerated, possibly with private sector partnerships.

e. Human resource development. A competitive labor force is key to Moldova's future development. Ensuring that the educational system is aligned with European trends and requirements and is responsive to labor market needs will be important. Improving the incentives to health care providers to both improve efficiency and deliver quality health services will be critical in Moldova's efforts to meet the MDGs.

\section{B. Suggested Issues for Discussion}

37. In considering the NDS and associated JSAN, Executive Directors may wish to focus on the following issues:

a. Do Directors agree with the staffs' view that the NDS focuses on the appropriate areas for poverty reduction?

b. Do Directors concur with the priority areas for implementation identified by staffs and the staffs recommendation to further work on incorporating those areas into the medium-term expenditure framework? 